\title{
Penerapan Viewboard Technomedia Journal menggunakan sistem iLearning Journal Center pada Perguruan Tinggi
}

\author{
Untung Rahardja ${ }^{1}$ \\ Indri Handayani ${ }^{2}$ \\ Randy Wijaya ${ }^{3}$ \\ Dosen STMIK Raharja ${ }^{1,2}$, Mahasiswa STMIK Raharja ${ }^{3}$ \\ E-mail: Untung@ raharja.info ${ }^{1}$, Indri@ raharja.info ${ }^{2}$, Randy@ raharja.info ${ }^{3}$
}

\begin{abstract}
ABSTRAK
Perkembangan teknologi informasi yang semakin cepat dan selalu memberikan inovasi dalam membuat suatu karya yang kreatif dan bermanfaat dalam memberikan informasi sama dengan hal nya Perguruan Tinggi Raharja yang sangat membutuhkan informasi dan sistem informasi yang akurat,cepat dan efisien. untuk menunjang keaktifan penulis karya ilmiah atau jurnal dengan TMJ merupakan sebuah sistem pelayanan penulisan karya ilmiah atau jurnal dari hal memberitahukan informasi pembukaan jurnal, template jurnal dan submit jurnal dengan tujuan, memberitahukan kepada seluruh mahasiswa sehingga tidak mengalami kekurangan dalam informasi mengenai jurnal adapun tujuan dari Viewboard TMJ adalah sebagai tempat pelayanan informasi dari data-data yang sudah ada dan terkait dengan penulisan karya ilmiah atau jurnal sehingga nanti nya akan menampilkan informasi yang valid juga dapat mudah untuk di pantau dengan menggunakan berbasis komputer, hal ini memudahkan admin untuk mengolala data yang terdapat pada TMJ menjadi sebuah Viewboard. Viewboard ini berbasis web karena Viewboard yang diterapkan untuk menampilkan informasi menggunakan website
\end{abstract}

Kata kunci : TMJ, Viewboard, Journal

\begin{abstract}
The rapid development of information technology and always provide innovation in making a creative and useful work in providing information similar to Raharja High School which is in desperate need of information and information system that is accurate, fast and efficient. to support the activeness of the author of a scientific or journaling work with TMJ is a system of writing service of scientific papers or journals of the matter informing the opening of the journal, journal template and submit the journal with the purpose, notify all students so that there is no shortage in information about journals as for the purpose of Viewboard TMJ is as a place of information services from existing data and related to the writing of scientific papers or journals so that later it will display valid information can also be easy to monitor by using a computer-based, it is easier for the admin to mengolala data contained in TMJ becomes a Viewboard. This Viewboard is web based because the Viewboard is applied to display information using the website.
\end{abstract}


Keywords: TMJ, Viewboard, Journal

\section{PENDAHULUAN}

Berkembangannya Perguruan Tinggi Raharja di dunia teknologi dan informasi, kemudian dengan perkembangan yang sangat amat pesat, diterapkanlah sebuah website yang digunakan untuk memberikan informasi data serta kemudahan untuk para mahasiswa untuk mengirimkan file penulisan karya ilmiah atau jurnal dan terdapat informasi layak atau tidak nya jurnal yang sudah di kirim oleh mahasiswa dan di eksekusi kembali dengan Viewboard TMJ

Website adalah World Wide Web dapat diartikan sebagai kumpulan halaman yang menampilkan informasi data teks, data gambar diam atau bergerak data animasi suara,video dam atau gabungan dari semuanya, baik yang bersifat statis ataupun dinamis yang berbentuk rangkaian bangunan yang saling terkait dimana masing-masing dihubungkan dengan jaringan-jaringan halaman-halaman situs yang tersimpan dalam sebuah server/hosting, dan teridentifikasi melalui sebuah nama yang disebut juga sebagai domain atau sub domain.

Saat ini Ilearning Journal Center sedang menerapkan suatu pembaharuan terhadap sistem dengan cara memberikan informasi penulisan karya ilmiah atau jurnal bisa tersimpan baik yang disebut Viewboard TMJ, dengan adanya Viewboard TMJ, data dan informasi nya mudah untuk dimonitoring oleh seluruh mahasiswa.

iJC adalah sebuah inovasi sistem jurnal elektronik (e-journal) pada penerapannya dijadikan arahan untuk dapat menggantikan sistem pengelolaan jurnal konvensional (tercetak ), iJC dengan menggunakan Open Journal System (OJS) dari PKP ( Public Knowledge Project) sebagai dasarnya mampu memberikan kemudahan,kecepatan, serta integritas dalam melakukan pengelolaan jurnal. Technomedia Journal (TMJ) sudah mendapatkan 6 (enam) indeksasi. Mitra Bestari yang dimiliki oleh Technomedia Journal (TMJ) pun merupakan terbaik. Serta kemudahan akses internet dan ketersediaan perangkat teknologi informasi, kini lebih mudah membaca jurnal dalam format elektronik karena bisa diakses dimana pun dengan koneksi internet sehingga mudah mendapatkannya.

Technology Partners (2014), Viewboard adalah apllikasi custom yang dibuat oleh mitra teknologi dengan ini kamu mendapatkan informasi penting yang kamu butuhkan untuk mengambil sebuah keputusan, memiliki satu dasboard untuk meningkatkan sebuah informasi, kamu dapat menghubungkan ke sistem $\mathrm{cms}$ atau mengakses database. Dari definisi tersebut dapat disimpulkan bahwa Viewboard adalah aplikasi custom yang berperan penting untuk menampilkan informasi yang dibutuhkan

Sebelum diterapkan nya sistem TMJ Ilearning Journal Center telah memliki sebuah sistem yaitu iJC (Ilearning Journal Center) iJC adalah sebuah inovasi sistem pengelolaan jurnal elektronik (e-journal) yang pada penerapannya diarahkan untuk dapat menggantikan sistem pengelolaan jurnal konvensional (tercetak), iJC dengan 
menggunakan Open Journal System (OJS) dari PKP (Public Knowledge Project) sebagai dasarnya mampu memberikan kemudahan,kecepatan, serta integritas dalam melakukan pengelolaan jurnal

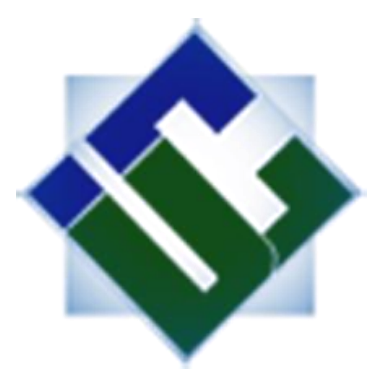

Gambar 1. Logo iJC (iLearning Journal Center)

Sumber : journal.ilearning.co

\section{METODE PENELITIAN}

Pada penelitian kali ini penulis menggunakan metode implementasi. menurut implementasi atau pengujian adalah tahapan dimana software yang telah selesai dikembangkan dilakukan pengujian dengan metode blackbox agar semua komponen sistem apakah sesuai dengan analisis kebutuhan pada awal perancangan". Implementasi pada program sistem Viewboard Technomedia Journal Pada Perguruan Tinggi Raharja dilakukan dengan menggunakan Blackbox testing. Blackbox Testing adalah pengujuan untuk mengetahui fungsi-fungsi perangkat lunak yang telah berjalan sesuai dengan kebutuhan.

Proses pengumpulan data yang penulis lakukaan, mulai dari observasi mengenai OJS, wawancara kepada pihak-pihak terkait, serta studi pustaka yang dilakukan oleh penulis, seperti mempelajari laporan penelitian, buku-buku, karangan ilmiah dan sumber-sumber lain yang berhubungan dengan sistem validasi hibah pada penilaian objektif. Berikut ini adalah daftar literature review yang digunakan dalam penelitian ini:

1. Penelitian yang dilakukan oleh Nursam Soemantri (2015)Penelitian yang berjudul "Perancangan Viewboard iDuHelp! Menggunakan Bootstrap Sebagai Penunjang Laporan Perfoma iDuHelp! Online Pada Perguruan Tinggi”. Penelitian ini membahas dimana Dengan adanya Viewboard iDuHelp! nantinya dapat mengeluarkan suatu informasi mengenai top operator iDuHelp! dan top customers dan history performa operator iDuHelp! Online perbulan, fungsi dari Viewboard itu sendiri untuk menunjang pelayanan iDuHelp! agar lebih baik lagi, sehingga PIC (Person In Charge) iDuHelp! tidak membuat laporan performa operators iDuHelp! online secara manual lagi dan terotomatis terekap pada Viewboard iDuHelp!. di dalam Viewboard juga akan ada informasi mengenai daftar operator iDuHelp!, 
fasilitas FAQ, Viewboard juga dapat terkoneksi dengan iMe iDuHelp!, forum RhjFox dan Viewboard Rooster, juga akan ada daftar operator dan terakhir last log operator pada sistem iDuHelp!.

2. Penelitian yang dilakukan oleh Ika Amalia (2016)Penelitian yang berjudul "Perancangan Viewboard GO+ Sebagai Penunjang Laporan Pembayaran Mahasiswa Pada Perguruan Tinggi" Penelitian ini membahas dimana dirancangnya sebuah Viewboard $\mathrm{GO}+$ yang dapat diakses secara online melalui sebuah website guna mempermudah mahasiswa, selain itu staff kasir pun dapat dengan mudah memonitoring data history pembayaran mahasiswa sebagai penunjang laporan bagian keuangan kepada pimpinan. Lalu akan ada juga informasi mengenai mutu pemanfaatan dari GO+ itu sendiri yang terdiri dari berapa jumlah user yang masuk pada Viewboard GO+. Untuk merumuskan perancangan Viewboard dimungkinkan dengan menggunakan metode analisa sistem elisitasi. Fungsi dari ""Viewboard"" ini untuk mempermudah mahasiswa melihat hasil history pembayarannya secara online melalui website yang tersedia, dan juga sebagai menunjang pelayanan keuangan agar lebih akurat lagi.

3. This research was conducted by Anatoliyovych Rusol Karralli, Joyce Tipton, Doina Dumitru, Lisa Scholz and Santhi Masilamani (2015)Study entitled "Development of a metrics dashboard for monitoring involvement in the Drug Pricing Program, s.a." the study discussed In recent years there has been heightened congressional and regulatory scrutiny of the federal program, s.a., which provides discounted drug prices on Medicaid-covered drugs to safety net hospitals and other healthcare organizations, s.a.-eligible, or "covered entities." Historically, the program has lacked s.a. a metrics-driven reporting framework to help covered entities capture the value of community involvement programs, s.a., benefits provided to underserved populations, and costs associated with compliance with s.a. eligibility requirements. The u.s. is part of an initiative by a large health system to optimize its utilization program, s.a. and regulatory compliance efforts, a team of pharmacists led the development of an electronic dashboard tool to help monitor program activities at the s.a. system's s.a.-eligible facilities. After soliciting input from an array of internal and external stakeholders, the program s.a. team designed the dashboard and the associated data-entry tools to facilitate the capture and analysis of program-related data, s.a. in four domains: cost savings and revenue, program maintenance costs, community benefits, and compliance.

4. Penilitian ini dilakukan oleh Isma Damayanti (2015)Penelitian yang berjudul "Analisa Perancangan Sistem Viewboard Zorilia dengan Menggunakan Metode Gamification Studi Kasus: Perguran Tinggi Raharja". Penelitian ini membahas Dimana Zorilia menggunakan platform iLearning gamification untuk membuat bekerja dan belajar terasa seperti bermain. Segala bentuk pekerjaan dapat dilakukan disini agar tidak ada yang terlewat, menjadi suatu kombinasi yang sangat sempurna. Ditambah lagi, perancangan Viewboard ini menjadi penyempurna konsep 
gamification karena ranking semua user terangkum di dalam Viewboard dan akan menjadi motivasi tersendiri untuk para user agar selalu menjadi no 1 di dalam Viewboard. Konsep gamification ini sama halnya dengan konsep 4b yaitu belajar, bekerja, bermain dan berdoa yang sebelumnya sudah diterapkan pada Perguruan Tinggi Raharja. Dengan konsep ini user dapat menyelesaikan to do list nya dengan baik. Sistem Zorilia ini juga merupakan salah satu bagian dari Future IT Raharja (FIR).

5. This research was conducted by Carl Christer-Nilsson (2015) Study entitled "User Centered Design of a Monitoring Dashboard For Better Energy Performance" The objective of the thesis is to produce visualization of production data in the form of a visually efficient dashboard for monitoring production on an assembly line. The aim is to influence the users' behavior, so that they act in an energy saving manner by regarding the visualization provided by the dashboard. A long term secondary effect is to make the end-users aware of the waste, and as a consequence feel encouraged to cut down on the unnecessary energy use. The theory behind the result is based in the field of Human Factors Engineering and Situation Awareness. The thesis project has been carried out in Volvo M1 facility at Lindholmen, Göteborg and at the MD 16 line, Volvo PowerTrain in Skövde.

\section{HASIL DAN PEMBAHASAN}

\subsection{Analisa Permasalahan}

Menurut data observasi yang sudah peneliti jalani yaitu Viewboard Technomedia Journal tersebut masih sangat manual dan dalam informasi masih mengalami masalah yang telah peneliti analisa :

a. Pencarian

Yang terjadi saat ini sebelum adanya Viewboard Technomedia Journal, Mahasiswa tidak bisa mengetahui apakah penulisan karya ilmiah nya sudah layak terbit atau belum masih dalam pemberitahuan melalui email

b. Informasi

Informasi yang diberikan kepada mahasiswa belum secara keseluruhan baik dikarenakan dalam penyampaian nya masih kurang sehingga mahasiswa terkadang tidak mengetahui pemberitahuan dari pihak Technomedia Journal.

c. Penerbita

Saat ini adalah setiap mahasiswa yang sudah submit jurnal nya di Technomedia Journal, mahasiswa harus menunggu untuk penerbitanya, kemudian saat ingin menerbitkan nya kendala nya adalah mahasiswa belum revisi jurnal nya dan informasi nya belum di dapatkan dari pihak Technomedia Journal. 
Berdasarkan data yang sudah dapatkan terbukti bahwa masih ada kekurangan didalam Technomedia Journal

\subsection{Rancangan program pada usecase diagram}

Dalam merancang program peneliti menggunakan usecase diagram sebagai gambaran sistem yang berjalan. Untuk rancangannya bisa di liat pada gambar di bawah ini

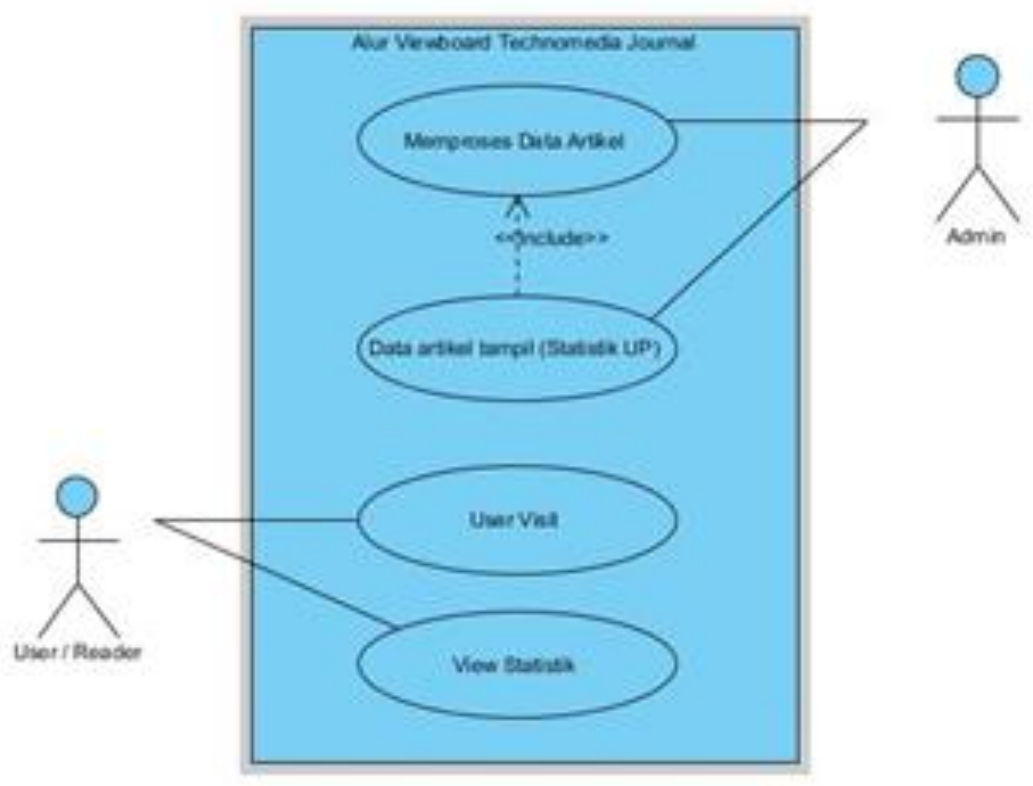

Gambar 1. Usecase diagram

Pada gambar usecase diagram diatas dapat diusulkan, Terdapat Use Case submit artikel dan diikuti oleh actor yaitu author kemudian Main success scenario yaitu Author submit artikel pada sistemTechnomedia Journal, kemudian Use Case Memproses data Artikel dengan adanya Actor nya yaitu Editor dilanjutkan dengan Main success scenario : Editor men-generate atau memproses data artikel, dilanjutkan Use Case menampilkan Viewboard (data tampil) dan actor nya yaitu editor dilanjutkan dengan main success scenario yang berisi, Setelah editor memproses data artike kemudian data artikel tersebut tampil. Use Case author Visit iJC actor sebagai author dan main success scenario nya adalah Author atau pembaca mengunjungi official site iLearning Journal Center, Use Case Open Technomedia Actor sebagai author dan main successs scenario adalah : Author atau pembaca setelah mengunjungi official site iLearning Journal center kemudian akan di lanjutkan kepada halaman Technomedia Journal, Use Case View Viewboard Actor sebagai author dan main success scenario adalah Author atau pembaca seteleha 
mengunjungi official site iLearning Journal Center kemudian akan di antarkan kepada halaman Technomedia Journal setelah itu author akan melanjutkan kepada Viewboard Technomedia Journal

\subsection{Rancangan Flowchart}

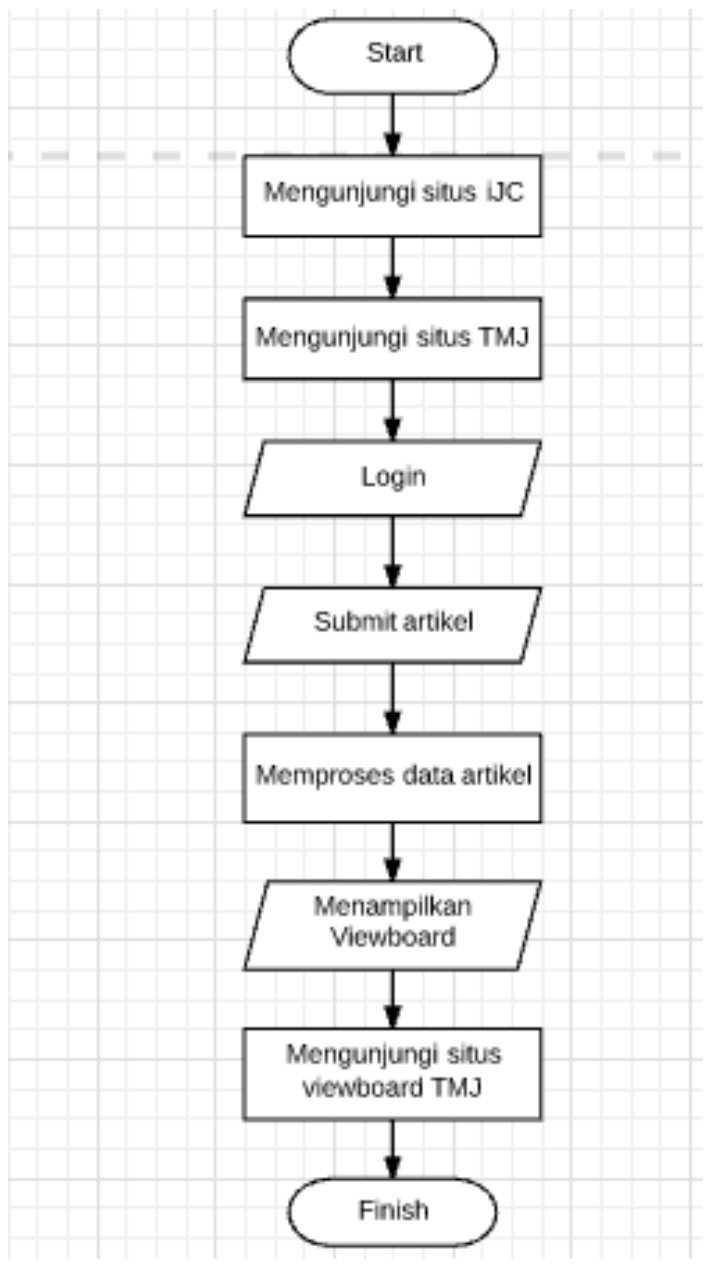

Gambar 2. Rancangan Flowchart

Dapat dijelaskan pada gambar Flowchart dalam proses submit artikel sampai pada mengunjungi Viewboard Technomedia Journal pada saat ini yaitu terdiri dari:

1. 2 (dua) simbol terminal, yang berperan sebagai "start" dan "end" pada aliran proses flowchart untuk mengakses Viewboard Technomedia Journal.

2. 7 (tujuh) simbol data, yaitu menyatakan proses input atau output tanpa tergantung jenis peralatnnya, yaitu akses "Viewboard Technomedia Journal" yang mempunyai akses data secara public atau umum. 


\subsection{Implementasi Program}

\subsubsection{Tampilan Menu awal pada TMJ}

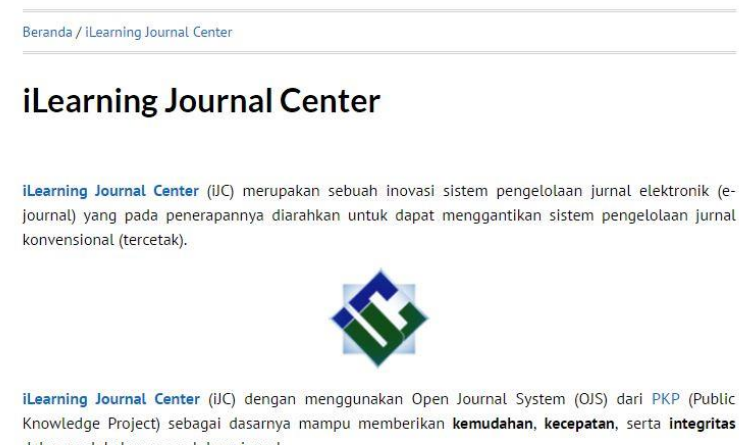
dalam melakukan pengelolaan jurnat.
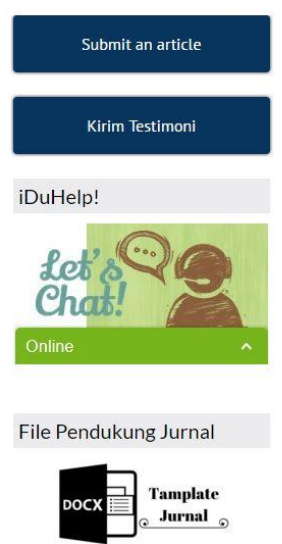

Gambar 3. Tampilan Menu iJC

Sumber : ijc.ilearning.co

Pada gambar 3 di atas adalah tampilan menu pada iJC dimana pada halaman ini tersedia sub menu apa yang kita inginkan seperti pada gambar diatas terdapat template jurnal nya sebelum ingin memulai penulisan karya ilmiah

\subsubsection{Tampilan Menu Login}

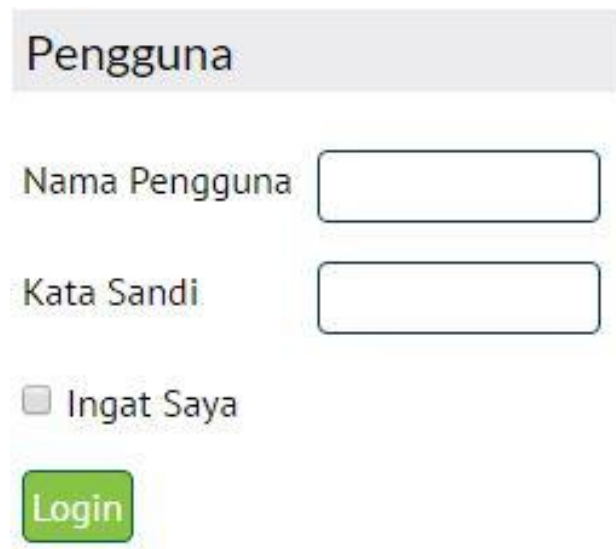

Gambar 4. Tampilan Menu Login

Sumber : ijc.ilearning.co

Pada gambar 4 di atas adalah halaman yang berfungsi untuk menu login yang dimana digunakan user untuk memasuki halaman utama atau dashboard aplikasi. 


\subsubsection{Tampilan Menu TMJ}

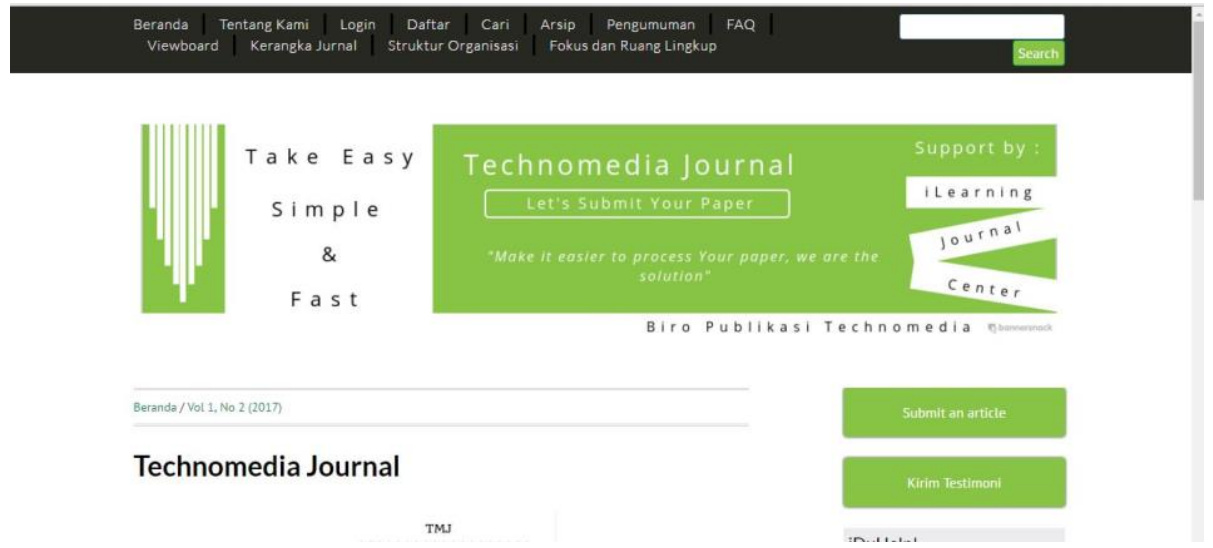

Gambar 5. Tampilan Menu Pada TMJ

Sumber : ijc.ilearning.co

Pada gambar 5 di atas adalah tampilan menu pada TMJ disana ada beberapa sub menu yang memudahkan para pengguna TMJ untuk mempelajari nya dan mudah untuk mengeksekusi apa yang di inginkan

\subsubsection{Tampilan Menu login berhasil pada TMJ}

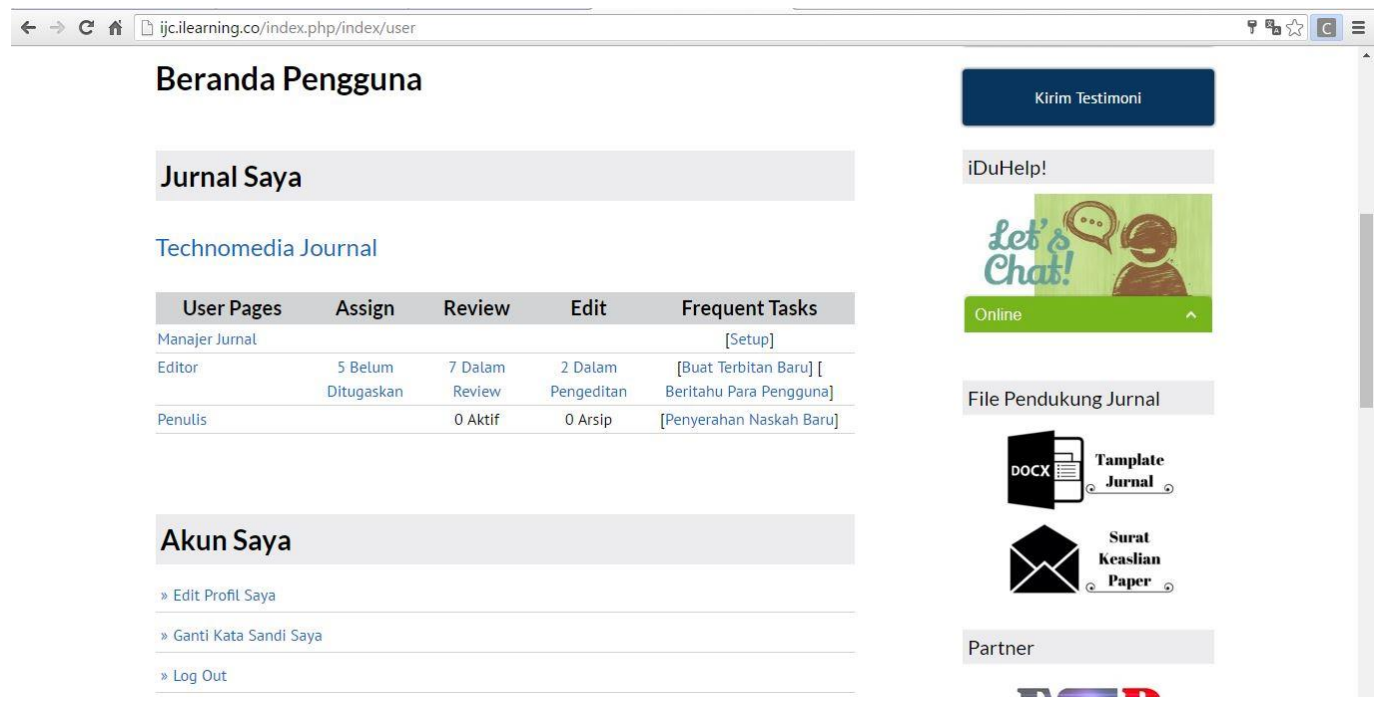

Gambar 6. Tampilan Menu berhasil login pada TMJ

Sumber : ijc.ilearning.co

Pada gambar 6 pada gambar diatas menjelaskan ketika sudah login pada TMJ akan berlanjut pada halaman ini, dihalaman ini menjelaskan isi dari reviewer dan author atau ada kegiatan dalam pensubmitan jurnal pada TMJ 


\subsubsection{Tampilan Menu Awal pada Viewboard TMJ}

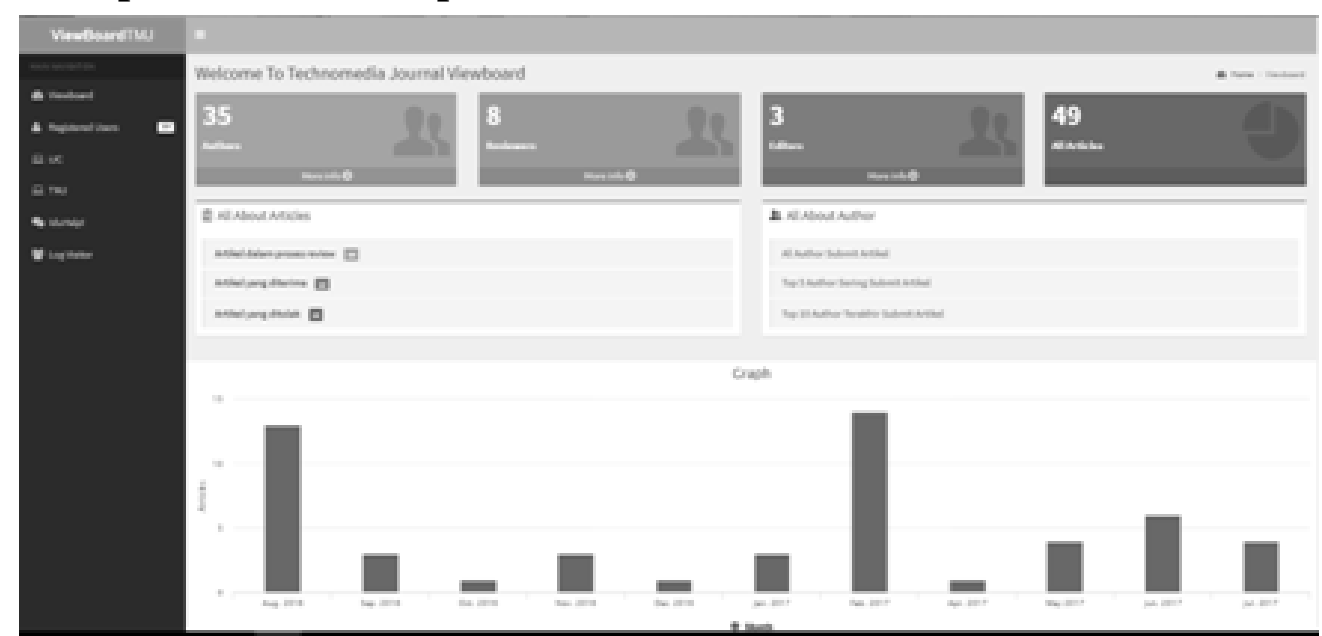

Gambar 7. Tampilan Menu awal Viewboard TMJ

Sumber : ijc.ilearning.co

Pada gambar 7 di atas ini menu awal pada Viewboard TMJ digambar menampilkan angka dan grafik untuk memberikan sebuah informasi kepada seluruh mahasiswa .

\subsubsection{Tampilan Registers Users}

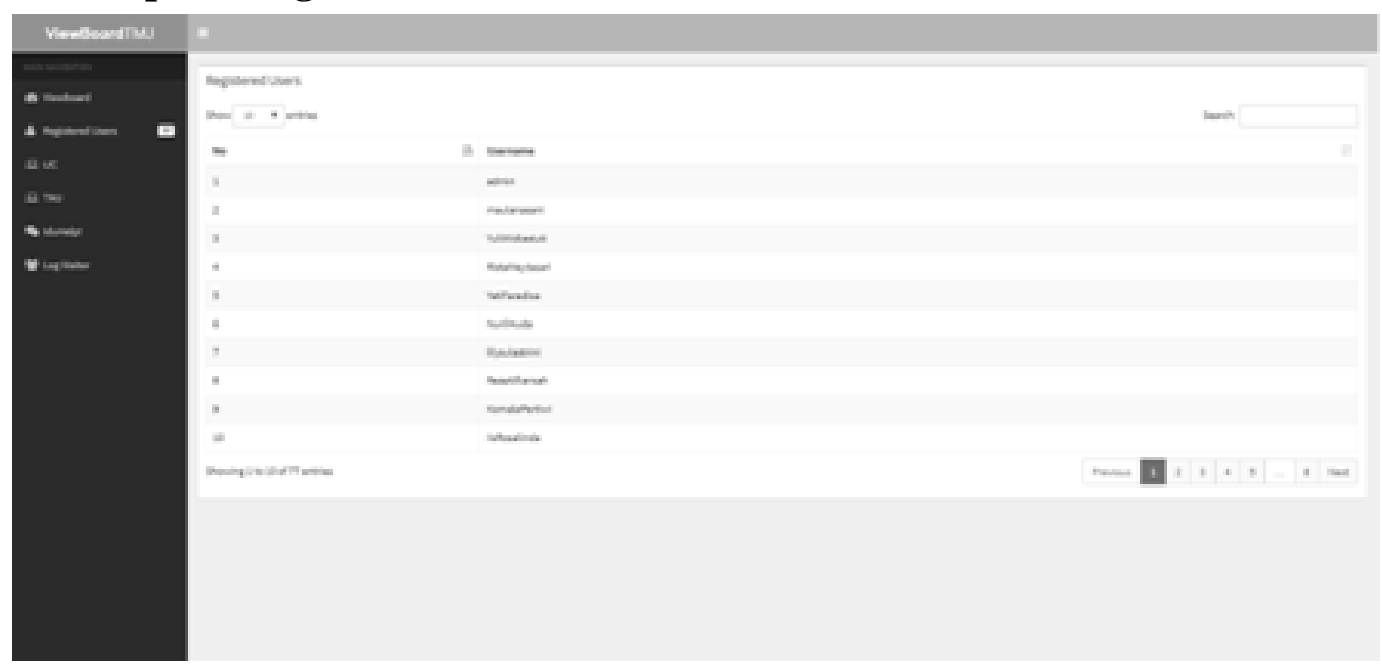

Gambar 8. Tampilan Registers Users

Sumber : ijc.ilearning.co

Pada gambar 8 di atas untuk registers users ini kita bisa melihat keseluruhan akun users dan siapa saja yang sudah terdaftar pada TMJ. 


\subsubsection{Tampilan Menu All Author Submit Artikel}

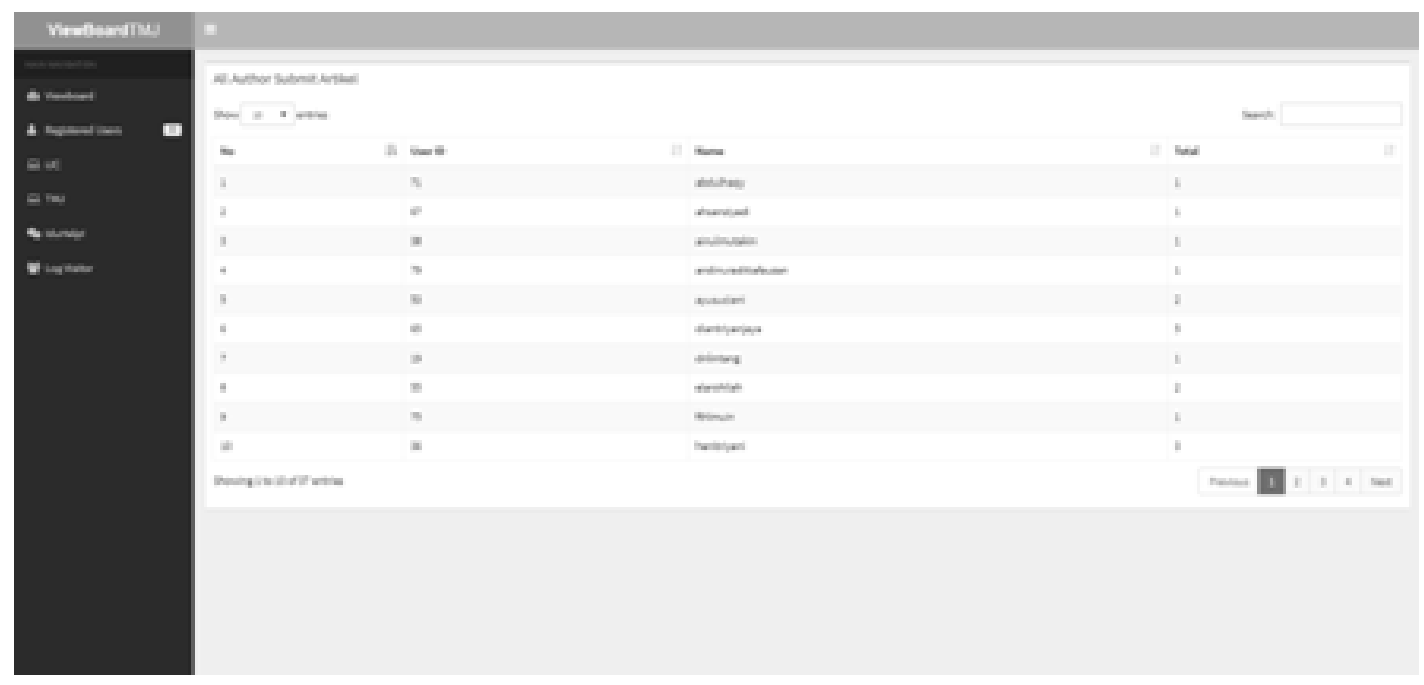

Gambar 9. Tampilan Menu All Author Submit Artikel

Sumber : ijc.ilearning.co

Pada gambar 9 di atas ini menampilkan menu penulis karya ilmiah nya dan menampilkan angka informasi nya

\subsubsection{Tampilan Grafik}

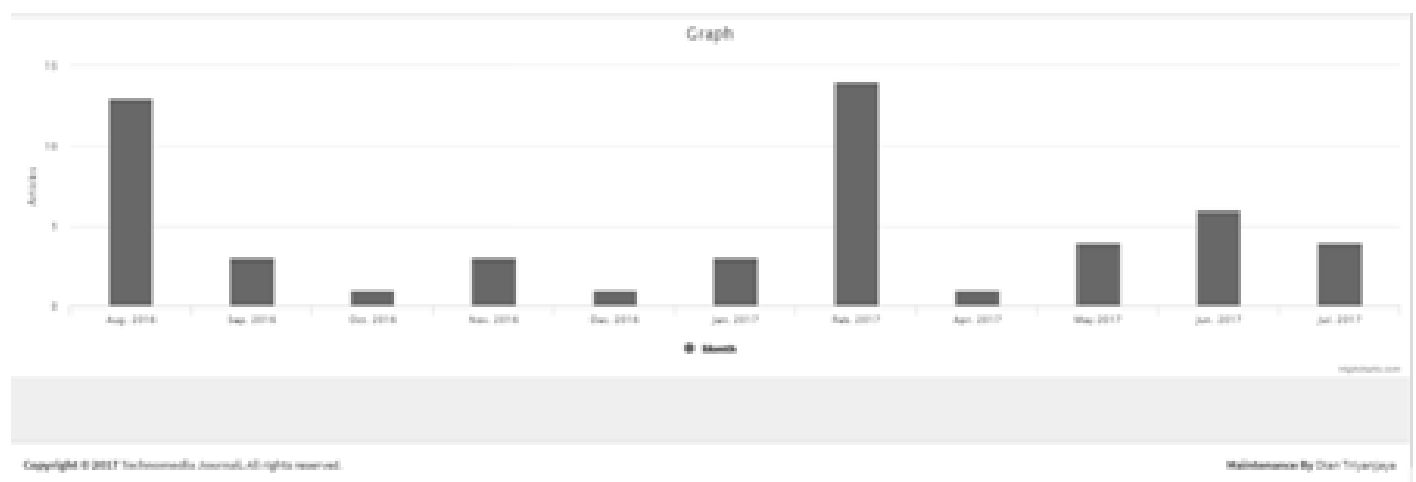

Gambar 10. Tampilan Grafik

Sumber : ijc.ilearning.co

Pada gambar 10 di atas ini menampilkan menu grafik agar mahasiswa bisa mengetahui informasi apa saja yang ditampilkan dialam Viewboard. 


\section{KESIMPULAN}

Berikut ini adalah kesimpulan perihal rumusan masalah mengenai pemgembangan E-Journal Technomedia Journal pada iLearning Journal Center di Perguruan Tinggi sebagai berikut :

1. Jika Sebelumnya sistem hanya menampilkan data statistik, dan author belum dapat mengetahui keseluruahn informasi yang ada pada sistem Technomedia Journal, maka saat ini dengan adanya Viewboard TMJ ( Technomedia Journal ) ini, author dapat mengetahui keseluruhan informasi seputar status dan aktfitas artikel pada sistem Technomedia Journal

2. Jika sebelumnya sistem belum dapat menampilkan informasi yang informatif dan user friendly untuk mempermudah author melihat informasi seputar status artikel dan lain-lain

3. jika sebelumnya belum adanya sebuah Viewboard yang bisa memberikan sebuah informasi bedasarkan yang ada pada sistem Technomedia Journal dan saat ini sudah ada Viewboard TMJ (Technomedia Journal) yang dapat memberikan sebuah informasi kepada author mengenai informasi seputar status artikel yang bedasarkan pada sistem Technomedia Journal.

\section{SARAN}

Untuk meningkatkan Viewboard Technomedia Journal, penulis memberikan beberapa saran yaitu :

1. Sosialisasikan sitem Technomedia Journal dan Viewboard Technomedia Journal kepada seluruh mahasiswa Perguruan Tinggi Raharja agar mengetahui apa itu Technomedia Journal dan seputar informasi mengenai Technomedia Journal

2. Diharapkan agar pihak pengembang selanjutnya dapat menampilkan data yang belum bisa ditampilkan

3. Dan diharapkan agar pengembang selanjutnya dapat membuat Viewboard Technomedia Journal berbasis Mobile agar mempermudah user/ author mendapatkan informasi dimana saja kapan saja hanya dengan menggunakan smartphone dan tab.

\section{DAFTAR PUSTAKA}

[1] Tiara, K., Nurhaeni, T., \& amalia, I. (2016). Penerapan Viewboard GO+ Berbasis Yii Sebagai Media Monitoring Pembayaran Mahasiswa. Technomedia Journal, 1(1), 65-77. Diambil dari http://ijc.ilearning.co/index.php/TMJ/article/view/17/13

[2] Rahardja, U., Handayani, I., \& Setiani, L. (2017). Viewboard Sebagai Laporan Jumlah Keseluruhan Artikel Pada iLearning Raharja Ask and News. CogITo Smart Journal, 3(1), 42-55. 
[4] Thwari, Amit S. dan Dr. S.E Yedey.2016.Study Of Codeigniter Technology. International Journal of Research in Computer \& Information Technology. Vol. 2 No.2.

[5] Lee, Sunguk. 2012. Unified Modeling Language (UML) for Database Systems and Computer Applications. International Journal of Database Theory and Application. Vol.5 No.1.

[6] Soemantri, Nursam. 2015 Perancangan Viewboard iDuHelp! Menggunakan Bootstrap Sebagai Penunjang Laporan Perfoma iDuHelp! Online Pada Perguruan Tinggi.

[7] Amalia, Ika. 2016 Perancangan Viewboard GO+ Sebagai Penunjang Laporan Pembayaran Mahasiswa Pada Perguruan Tinggi

[8] Karalli, Rusol., Joyce Tipton Doina Dumitru., Lisa Scholz., Santhi Masilamani. 2015. Development of a metrics dashboard for monitoring involvement in the Drug Pricing Program, s.a. American Journal of Health-System Pharmacy September 1, 2015 vol. 72 no. 17 1489-1495.

[9] Damayanti, Isma . 2015. Analisa Perancangan Sistem Viewboard Zorilia dengan Menggunakan Metode Gamification Studi Kasus: Perguran Tinggi Raharja

[10] Christer-Nilsson, Carl. 2015. User Centered Design of a Monitoring Dashboard For Better Energy Performance. Sweden: CHALMERS UNIVERSITY OF TECHNOLOGY 